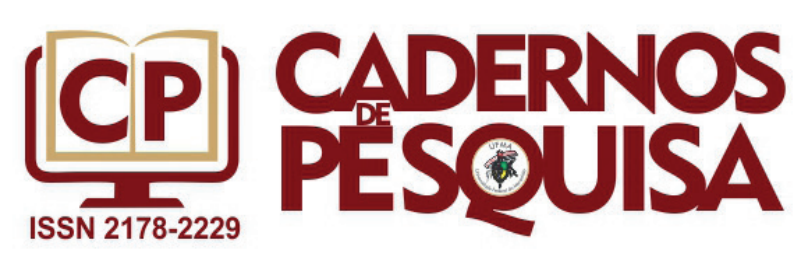

\title{
PRODUÇÕES ACADÊMICAS SOBRE OS INSTITUTOS FEDERAIS DE EDUCAÇÃO NO RS: ANÁLISE DOS MOVIMENTOS DOS SENTIDOS ${ }^{1}$
}

\author{
ACADEMIC PRODUCTIONS ABOUT THE INSTITUTOS \\ FEDERAIS DE EDUCAÇÃO IN RS: AN ANALYSIS OF THE \\ MOVEMENTS OF THE SENSES
}

Liliana Soares Ferreira ${ }^{2}$

ORCID: $h$ ttp://orcid.org/0000-0002-9717-1476

Álvaro Moreira Hypolito ${ }^{3}$

ORCID: $h$ ttp://orcid.org/0000-0003-1487-0413

\begin{abstract}
Resumo: $O$ artigo sistematiza pesquisa que objetivou analisar a produção acadêmica sobre os Institutos Federais de Educação - IFs no Rio Grande do Sul/RS, em programas gaúchos de pós-graduação em Educação, entre 2009 e 2020. Tal estudo justifica-se pelo interesse em conhecer como está se constituindo a pesquisa nos cursos stricto sensu em EPT. Ao mesmo tempo que se descreve o estudo em cento e trinta e três trabalhos selecionados, demonstra-se como o corpus da pesquisa foi abordado, com base na Análise dos Movimentos de Sentidos (AMS). Além de indicar a dificuldade para realização desse modo de investigação em repositórios, a pesquisa permitiu que se percebesse a necessidade de uma rede de pesquisadores e de produções mais articuladas sobre Educação Profissional e Tecnológica como política educacional e, inserida nela, sobre os Institutos Federais de Educação no Estado. Quanto aos dados produzidos, a pesquisa possibilitou visualizar que os Institutos, embora mencionados nos títulos, na maior parte dos trabalhos, são apenas o contexto onde outras temáticas são estudadas, sendo as principais: formação e trabalho dos professores, currículo e PROEJA. Dessa forma, apenas dez por cento dos trabalhos versa efetivamente sobre os IFs, descrevendo-os como instituições em processo de implementação no Estado.
\end{abstract}

Palavras-chave: Educação Profissional e Tecnológica, políticas educacionais, análise dos movimentos de sentidos, pesquisa em educação.

1 Artigo com base em projeto de pesquisa desenvolvido com financiamento pelo EDITAL FAPERGS/CAPES 04/2018 - PROGRAMA DE BOLSAS DE FIXAÇÃO DE DOUTORES - DOCFIX, n. 18/2551-0000550-9 e EDITAL FAPERGS 05/2019 - PROGRAMA PESQUISADOR GAÚCHO-PQG, n. 19/2551-0001828-2, produzido durante o estágio pós-doutoral no Programa de Pós-graduação em Educação, da Faculdade de Educação, da Universidade Federal de Pelotas.

2 Doutorado em Educação. Professora do Programa de Pós-graduação em Educação. Universidade Federal de Santa Maria - UFSM, Santa Maria - RS

3 Doutorado $(\mathrm{PhD})$ em Curriculum and Instruction na Universidade de Wisconsin - Madison. Professor do Programa de Pós-graduação em Educação. Universidade Federal de Pelotas - UFPEL, Pelotas - RS 


\begin{abstract}
The article systematizes research that aimed to analyze the academic production on the Institutos Federais de Educação - IFs in Rio Grande do Sul / RS, in postgraduate programs in Education, between 2009 and 2020. This study is justified by the interest in knowing how the research in stricto sensu courses in EPT is being constituted. At the same time that the study is described in one hundred and thirty-three selected works, it demonstrates how the corpus of the research was approached, based on the Analysis of the Movement of Senses (AMS). In addition to indicating the difficulty in carrying out this mode of investigation in repositories, the research allowed us to perceive the need for a network of researchers and more articulated productions on Vocational and Technological Education as an educational policy and, inserted in it, on the Institutos Federais de Educação in the State. As for the data produced, the research made it possible to see that the Institutes, although mentioned in the titles, in most of the works, are just the context where other themes are studied, the main ones being: teacher training and work, curriculum and PROEJA. Thus, only ten percent of the works effectively deal with the IFs, describing them as institutions in the process of being implemented in the State.

Keywords: Professional and Technological Education, educational policies, analysis of movements of meanings, research in education.
\end{abstract}

\title{
INTRODUÇÃO
}

O artigo sistematiza pesquisa realizada com o objetivo de analisar a produção acadêmica, dissertações e teses, sobre os Institutos Federais de Educação - IFs gaúchos, elaboradas em programas de pós-graduação de instituições de Ensino Superior - IES no Rio Grande do Sul/RS ${ }^{4}$. O critério inicial para seleção dos trabalhos foi a abordagem da temática, no período entre 2009 e 2020, ou seja, após a publicação da Lei 11.892, de 29 de dezembro de 2008, que instituiu a Rede Profissional e Tecnológica. Destaca-se que até junho de 2020, quando encerrada a pesquisa, não havia cadastro de trabalhos do ano de 2020, assim, a análise efetivamente foi realizada com trabalhos de 2009 a 2019.

Aplicou-se Análise dos Movimentos de Sentidos (AMS). Trata-se de fundamento teórico e metodológico desenvolvido pelo grupo de pesquisa no qual se trabalha ${ }^{5}$, que permite procedimentos de produção e análise de dados de modo dialético, visando a conhecer, analisar e sistematizar os sentidos em um discurso (FERREIRA, 2020a). Por dialética compreende-se o movimento em si. Nesse sentido a análise dialética possibilita uma investigação criativa, assim como um conhecimento ativo dos fenômenos e do mundo, não como são, mas como se transformaram em sua historicidade e podem ser doravante: "[...] o conhecimento é que é a própria dialética em uma das suas formas, o conhecimento é a decomposição do todo" (KOSIK, 2011, p. 18). Seguem a sistematização e a organização argumentativa, posteriormente a um estudo realizado. Ou seja, a sistematização é a produção de linguagem sobre o estudo, de modo organizado, porque submetido ao crivo analítico

4 O arquivo contendo o conjunto de trabalho analisados está disponível no site do projeto: https://www. ufsm.br/grupos/kairos/projetos

5 Refere-se ao Kairós - Grupo de Estudos e Pesquisas sobre Trabalho, Educação e Políticas Públicas, da Universidade Federal de Santa Maria/RS. 
dos pesquisadores. Nesse sentido, trata-se de produção do conhecimento, tendo por base a linguagem sob a forma de discursos (FERREIRA, 2020a). Nos discursos, os sentidos são provisórios e buscam se estabilizar, constituindo-se significados (FERREIRA, 2020a). Por isso, movimentos de sentidos.

Então, intencionou-se conhecer a produção acadêmica sobre os institutos federais gaúchos e, para tanto, realizou-se: a) pesquisa no Banco de Teses e Dissertações da CAPES - Coordenação de Aperfeiçoamento de Pessoal de Nível Superior ${ }^{6}$, com o descritor "instituto"; b) cotejamento dos dados encontrados nos repositórios institucionais e nos repositórios dos programas de pós-graduação com os descritores "instituto federal de educação" e "instituto"; c) uma vez encontrados os trabalhos, elaboraram-se tabelas tendo como índices a IES, o ano de defesa, o título, o nome do autor(a), o tipo de trabalho: dissertação ou tese; d) passou-se à leitura dos resumos e do texto, objetivando responder às seguintes questões: qual a temática abordada? A temática refere-se aos institutos federais no Rio Grande do Sul? Como é descrita a metodologia? Há a descrição do contexto e da historicidade dos institutos? A estrutura do trabalho contempla os elementos básicos: problematização, objetivos, justificativa, fundamentação teórica, metodologia, análise dos dados? e) Quais obras e autores abordam a temática EPT ou correlatas citados no texto? O/a autor(a) trabalha no instituto federal sobre o qual pesquisou? Quais outros autores, ligados a Instituições de Ensino Superior - IES gaúchas, participaram das comissões de avaliação do trabaIho? As respostas a estas questões foram organizadas em tabelas, estudadas quanto aos sentidos, de modo comparativo, e, com base nesse estudo, elaboraram-se os argumentos que compõem este artigo.

Os programas de pós-graduação nos quais foram encontradas dissertações e teses sobre os Institutos Federais são os seguintes:

Quadro 01: Programas de Pós-graduação gaúchos que apresentam teses e dissertações abordando os Institutos Federais no Rio Grande do Sul

\begin{tabular}{|c|c|c|c|c|c|c|c|c|c|c|c|c|c|}
\hline PPGS/ IES & PUCRS & UCS & UPF & UNISC & UNISINOS & UFPEL & UFSM & FURG & UFRGS & UNILASALLE & ULBRA & UNIJUI & UERGS \\
\hline Educação & $\mathrm{x}$ & $\mathbf{x}$ & $\mathrm{x}$ & $\mathrm{x}$ & $\mathrm{x}$ & $\mathrm{x}$ & $\mathrm{x}$ & $\mathrm{x}$ & $\mathrm{x}$ & $\mathrm{x}$ & $\mathrm{x}$ & & $\mathrm{x}$ \\
\hline $\begin{array}{l}\text { Educação } \\
\text { nas Ciências }\end{array}$ & & & & & & & & & & & & $\mathrm{x}$ & \\
\hline $\begin{array}{l}\text { Educação } \\
\text { Profissional e } \\
\text { Tecnológica }\end{array}$ & & & & & & & $\mathbf{x}$ & & & & & & \\
\hline
\end{tabular}

Fonte: Os autores, com base nos dados dos trabalhos analisados, 2020.

6 O Banco de Teses e Dissertações da Capes foi criado em 2001, como um catálogo que objetiva "[...] facilitar o acesso a informações sobre teses e dissertações defendidas junto a programas de pós-graduação do país" (http://www.capes.gov.br/sala-de-imprensa/noticias/3316-banco-de-teses-da-capes-possui-mais-de-450-mil-resumos). No site, encontram-se os resumos e o link de acesso ao texto integral, cadastrados pelos programas. 
Por que estes programas e não outros? Como critério, a seleção considerou os programas acadêmicos, incluídos nas áreas de concentração Educação, Educação Ambiental, Educação nas Ciências e Interdisciplinar, na CAPES. Obteve-se registros de trabalhos sobre os institutos federais em treze IES no Estado, públicas federais e comunitárias. Em apenas uma IES, havia dois cursos de pós-graduação que atendiam estes critérios.

Mediante os critérios adotados, resultaram selecionados cento e trinta e três trabaIhos: oitenta e oito dissertações e quarenta e cinco teses, no período 2009-2019, cujo título ou resumo indicavam a abordagem de temática relacionada a um ou a todos os Institutos gaúchos. A primeira busca resultou em mais trabalhos. Entretanto, após a seleção prévia, e, quando necessário esclarecimento que exigiu a leitura da dissertação ou tese para comprovar o critério de seleção referente ao contexto de pesquisa, a quantidade de trabalhos analisados foi reduzida para cento e trinta e três. Isto porque, apesar de o título, entendido como evidência da temática do estudo realizado, indicar a possibilidade de a pesquisa ser contextualizada em um dos Institutos Federais, no texto, não havia essa referência e, portanto, o trabalho não foi considerado.

Cabe descrever ainda a dificuldade em se realizar pesquisa em repositórios na medida em que estes, sobretudo os institucionais, nem sempre estão atualizados; em alguns casos, estão inseridos em barras de menu com difícil acesso; muitas vezes, apresentam links que não permitem acesso aos trabalhos; ou ainda, não estão indexados ao repositório da IES, sendo necessário buscá-los dentro do site do Programa; pode também, evidenciar-se incompatibilidade entre o repositório dos programas e os dados na CAPES, na Plataforma Sucupira7; ou mesmo, pode acontecer a demora na atualização, pelas IES, dos dados referentes às defesas. Em relação a este último, por exemplo, mesmo que a pesquisa tenha sido realizada até junho de 2020, três trabalhos defendidos em 2018 e todos os defendidos em 2019 somente foram encontrados nos sites dos programas de pós-graduação e não se conseguiu visualizá-los no Catálogo da Capes. E este aspecto é relevante, pois dificulta este tipo de pesquisa, exigindo recriação dos procedimentos e cotejamentos entre os sites. Outra questão relevante diz respeito ao fato de esta pesquisa ter uma temporalidade determinada e somente pode ser avaliada em relação à sua validade no tempo. Se for repetida a pesquisa em qualquer outro momento, os resultados serão diferenciados. Portanto, investiga-se para um determinado objetivo e, mediante outro, há que se repetir a pesquisa.

Todas essas dificuldades e cuidados necessários geram insegurança nos pesquisadores quanto aos equívocos que possam vir a cometer na seleção dos trabalhos ao buscarem informações constantes em repositórios ou catálogos. Mesmo sabendo disso e aplicando recursos de compatibilização de dados, acredita-se ser possível alguma margem de equívoco. Assim, apresentar-se-á a análise dos dados produzidos, a seguir, e, devido

7 Trata-se de repositório de dados da CAPES que visa a se constituir em "[...] ferramenta para coletar informações, realizar análises e avaliações e ser a base de referência do Sistema Nacional de Pós-Graduação (SNPG)". In: https://www.capes.gov.br/avaliacao/plataforma-sucupira (acessado em 13 de agosto de 2019). 
aos aspectos mencionados, não se fará referência a "estado do conhecimento" ou "estado da arte", mas, como já referido, optou-se pela análise dos movimentos de sentidos em amostra de trabalhos, dissertações e teses, publicadas entre 2009 e 2020, pelos programas de pós-graduação em Educação gaúchos, antes referidos ${ }^{8}$.

Justifica-se a relevância desse texto ao considerar que se tem uma espécie de "metapesquisa", na medida em que é sistematizado estudo sobre a produção acadêmica sobre os IFs gaúchos na pós-graduação em Educação, em Instituições de Ensino Superior localizadas no Rio Grande do Sul, o qual indica e põe em relevo as características dessa produção. Ao mesmo tempo, explica-se como uma pesquisa, nessas bases, é realizada, tendo por fundamento teórico-metodológico a Análise dos Movimentos de Sentidos. Devido a essa escolha, a AMS é conceituada e caracterizada durante toda o texto, seja de forma direta ou mesmo indireta, ao evidenciar-se como a pesquisa foi realizada. Nesse intuito, as seções do texto tratam inicialmente de uma contextualização dos institutos federais no Rio Grande do Sul, sua historicidade e características; seguem as abordagens sobre estes institutos nos trabalhos analisados; na sequência, apresenta-se uma análise dos movimentos de sentidos gerada pela leitura dos trabalhos como conjunto de produção sobre a temática estudada e considerações finais que visam a alinhavar o trabalho realizado até o momento.

\section{UMA CARACTERIZAÇÃO DA TEMÁTICA: OS IFS NO RIO GRANDE DO SUL}

No Estado gaúcho são três os Institutos: Instituto Federal de Educação, Ciência e Tecnologia Farroupilha (IFFAR), Instituto Federal de Educação, Ciência e Tecnologia Sul-Rio-Grandense (IFSUL) e Instituto Federal de Educação, Ciência e Tecnologia Rio Grande do Sul (IFRS). Integram também a Rede de Educação Profissional e Tecnológica gaúcha duas escolas técnicas vinculadas à Universidade Federal de Santa Maria: Colégio Técnico Industrial/ CTISM e Colégio Politécnico.

Os Ifs no Estado são instituições longevas e originaram-se de Escolas Técnicas e Centros Federais de Educação Tecnológica existentes no Estado até 2008. Naquele ano, foram criados os três IFs hoje compostos, ao todo, com 41 campi, distribuídos pelo Rio Grande do Sul. Portanto, são instituições imersas na cultura local e conhecem as demandas sociais e econômicas das regiões onde estão instaladas. Corroborando esta argumentação, um dos trabalhos analisados, no resumo, contém a seguinte afirmação:

A partir da Lei $n^{0} 11.892 / 08$ temos no Brasil a constituição de uma nova arquitetura institucional junto ao Sistema de Educacional Brasileiro - em especial à Educação Superior - no contexto da Educação Profissional e Tecnológica (EPT): Institutos

8 Foi encontrado um único trabalho semelhante a este estudo ora apresentado. Trata-se de um estado da arte, que objetivou "verificar o contingente de produções apresentadas em eventos, publicações em periódicos, bem como dissertações de mestrado e teses de doutorado defendidas no Brasil sobre a referida temática, com o recorte temporal no período de 2005 a 2015" (MINEIRO \& LOPES \& SALES, 2017, resumo). 
Federais de Educação, Ciência e Tecnologia (IF's). Esta institucionalidade foi concebida como sendo estratégica no desenvolvimento da nação, alinhada ao mundo trabalho, aos arranjos produtivos, e ao fortalecimento da democracia e da cidadania na busca do desenvolvimento nacional, regional e local. A Educação Superior neste contexto se apresenta de forma emergente, pois a institucionalidade dos IF's, se efetiva a partir dos preceitos de inclusão, justiça social e equidade na formação de sujeitos. Uma gama multidiversa de sujeitos acabaram por adentrar este espaço "universitário", trazendo para os IF's um perfil diferenciado de alunado, distinto daqueles "tradicionalmente" conhecidos por professores e gestores (FONTOURA, 2018, resumo).

Durante os governos Luís Inácio Lula da Silva (2003-2011), consolida-se a Rede Federal de Educação Profissional e Tecnológica (FERREIRA, 2020b). Alguns momentos dessa consolidação consistiram na elaboração, discussão e divulgação de políticas educacionais, as quais regulavam o movimento de expansão da Rede:

Quadro 02: Políticas educacionais que contribuíram para a composição da Rede de Educação Profissional e Tecnológica durante os governos do Presidente Lula

\begin{tabular}{|l|l|}
\hline Parecer CNE/CES 277/2006 & $\begin{array}{l}\text { Instituiu nova forma de organização da Educação Profissional e } \\
\text { Tecnológica e propôs a criação de um conjunto de eixos } \\
\text { tecnológicos para os Cursos Superiores de Tecnologia }\end{array}$ \\
\hline Decreto 6.095/2007 & $\begin{array}{l}\text { Instituiu diretrizes para a organização e estabeleceu } \\
\text { características de criação de um IF }\end{array}$ \\
\hline $\begin{array}{l}\text { Chamada Pública MEC/ Secretaria de Educação } \\
\text { Profissional e Tecnológica (SETEC) 02/2007 }\end{array}$ & Possibilitou a apresentação de propostas de criação de IFs \\
\hline Portaria MEC/SETEC 116/2008 & Divulgou a relação dos aprovados na chamada pública 02/2007 \\
\hline $\begin{array}{l}\text { "Concepções e Diretrizes dos Institutos Federais de } \\
\text { Educação, Ciência e Tecnologia" }\end{array}$ & $\begin{array}{l}\text { Documento publicado pelo MEC contendo orientaçôes sobre a } \\
\text { implementação dos IFS }\end{array}$ \\
\hline Projeto de Lei 3.775/2008 & Propõe a criação da Rede Federal de EPT e os IFs \\
\hline Lei $11.892 / 2008$ & Institui a Rede Federal de EPT \\
\hline
\end{tabular}

Fonte: Os autores. com base nos dados encontrados no site do Ministério da Educacão - MEC. 2020

Analisando o lugar do Estado brasileiro nessa expansão, percebem-se aspectos não somente de regulação, mas de atendimento às demandas do mundo do trabalho, de modo a coaduná-los com o avanço neoliberal:

O Estado entende os IFs na perspectiva de contribuição para o processo de modernização e desenvolvimento do país, qualificando (neste caso, com a educação profissional e tecnológica) os cidadãos e, consequentemente, incluindo-os no mercado de trabalho, levando em conta os arranjos produtivos e os aspectos sociais, culturais locais. O Estado atende, por um lado, demandas sociais da população, por formação e elevação dos níveis de escolaridade para adquirirem as devidas condições de empregabilidade e, por outro, as demandas do capital que exigem qualificação da mão de obra, objetivando o aumento da produtividade e a elevação das taxas de lucro. (TURMENA \& AZEVEDO, 2017, p. 1073) 
Então, a criação da Rede Federal e, em decorrência, dos Institutos Federais, compatibilizou-se a prerrogativas relacionadas à organização da Educação Profissional neste contexto da sociedade capitalista, na qual o Estado assume as características demandadas pelo estágio e metabolismo social e "Como arena de confrontação, não somente expressa as vicissitudes das lutas sociais, as tensões dos acordos e desacordos de forças sociais, mas também as contradições e dificuldades de estabelecer uma ação unificada, coerente e marcada pelos parâmetros centrais de um projeto político específico" (TORRES, 1995, p. 110).

Essas tensões apresentam-se nos projetos de governo. Em argumentação bem localizada, por integrar a equipe de governo na época, Pacheco (2011) manifesta argumentos que, se considerada sua posição no processo de implantação da Rede Federal de Educação, têm valor histórico. Segundo o autor, a criação da Rede Federal, objetivou educar sujeitos para o mundo do trabalho, "[...] na direção de um novo mundo possível, capazes de superar a barbárie neoliberal e restabelecer o ideal da modernidade de liberdade, igualdade e fraternidade, sob a ótica das novas possibilidades abertas à humanidade neste princípio de século" (PACHECO, 2011, p. 17).

Por esses argumentos, entende-se por qual motivo foram reconfiguradas as escolas de Educação Profissional, já que muitas delas já eram Centro de Educação Federal, articulando-as sob a forma de Institutos naquele momento: "[...] os IF são criados, em grande medida, a partir de um tensionamento de forças entre os interesses de reprodução do capital e o papel do estado como concretizador destes interesses" (SCHWEDE \& LIMA FILHO, 2015, p. 01). Esses argumentos estão relacionados ao item 2 da justificativa que integra a Lei 11.892/08:

A presente proposta tem o objetivo de oferecer ao país um novo modelo de institui-
ção de educação profissional e tecnológica, aproveitando o potencial instalado nos
atuais Centros Federais de Educação Tecnológica - CEFETs, Escolas Técnicas Fe-
derais - ETFs e Escolas Agrotécnicas Federais - EAFs, para estruturar um conjunto
de Institutos que respondam de forma mais ágil e eficaz às demandas crescentes
por formação de recursos humanos, difusão de conhecimentos científicos e tecno-
lógicos e suporte aos arranjos produtivos locais (EM Interministerial nº 00118/2008/
MP/MEC).

A justificativa do governo denota otimismo, como que convencendo a população da necessidade de rearticulação da EPT. Entretanto, havia, ao mesmo tempo, preocupação com o processo de criação dos IFS de modo muito rápido, sobrepondo as questões de infraestrutura e de finalidade relativas à Educação Profissional: "A criação dos IFs deslocou essa centralidade para as questões de cunho organizativo, ou seja, para a estrutura administrativa das novas instituições, para a ocupação dos novos cargos criados e para a construção dos prédios, inclusive das reitorias" (MOURA, 2012, p. 63). 
Para fins de entender o que são essas instituições e sua importância para o sistema educacional, no artigo $2^{\circ}$, da Lei 11.892 , encontra-se a seguinte explicação: "Os Institutos Federais são instituições de educação superior, básica e profissional, pluricurriculares e multicampi, especializados na oferta de educação profissional e tecnológica nas diferentes modalidades de ensino, com base na conjugação de conhecimentos técnicos e tecnológicos com as suas práticas pedagógicas" (BRASIL, 2008, art. 02). E, na época, havia o discurso incentivando a crer na relação entre a expansão da EPT e a noção de desenvolvimento do país:

[...] o papel que está previsto para os Institutos Federais de Educação, Ciência e Tecnologia é o de garantir a perenidade das ações que visem incorporar, antes de tudo, setores sociais que historicamente foram alijados dos processos de desenvolvimento e modernização do Brasil, o que legitima e justifica a importância de sua natureza pública e afirma uma Educação Profissional e Tecnológica como instrumento realmente vigoroso na construção e resgate da cidadania e transformação social. (PACHECO, 2011, p. 23)

Esses aspectos contribuem para se ler o otimismo e a aposta na expansão da EPT, com a criação da Rede de Educação Profissional e Tecnológica. Uma defesa, nesses termos, também se faz presente em um dos trabalhos analisados:

Aos IFs, cabe a luta, luta por reafirmar seu compromisso com os homens e com a sociedade, através da oferta de cursos que promovam a emancipação do sujeito, tornando-o senhor de si, contribuindo para a formação de uma nova realidade, onde homens e mulheres se tornem protagonistas de suas histórias, capazes de se voltar contra a dominação, exclusão e alienação, provenientes de políticas que tentam manter a separação de classes e, por conseguinte, a desigualdade social. (GONÇALVES, 2017, p. 89)

Os primeiros anos da Rede foram de efetivo trabalho de implementação e indicavam um crescimento evidente. Nesse clima, são implantados os institutos federais no RS, cada um com suas peculiaridades, determinadas pela região de inclusão e pelas demandas socioeconômicas dessas regiões (FERREIRA, 2020b)

A seguir, apresentam-se considerações sobre como e com base em quais temáticas os IFs gaúchos são estudados em dissertações e teses. Importante destacar, desde já, que oito trabalhos citam um dos IFs no título, no resumo, porém o texto põe em relevo a temática escolhida e, neste caso, o IF apresenta-se apenas como o cenário, não se constituindo em centralidade na pesquisa, levando a acreditar que poderia ser dispensável citá-lo. Outro elemento que comprova este argumento é encontrar-se nove trabalhos que não citam como referências nenhuma obra ou autor que aborde sobre Educação Profissional e Tecnológica (destes, três são do grupo em que o IF é apenas cenário), apresentando referências somente sobre a temática estudada e não sobre EPT ou sobre os IFs, ainda que estes sejam citados no título e no resumo. 
$E$, finalizando esta seção, cabe destacar que esta historicidade, aqui brevemente descrita dos IFs aparece ${ }^{9}$, de algum modo, na maior parte dos trabalhos, ou seja, em cento e dezoito, estabelecendo relação entre a temática estudada e o contexto do IF como um todo ou com um de seus campi.

\section{UMA "METAPESQUISA"; CONSIDERAÇÕES SOBRE A TEMÁTICA COM BASE NA LEITURA DAS DISSERTAÇÕES E TESES}

Um dos ganhos em realizar-se a análise de produções acadêmicas é o quanto se aprende sobre escrita, argumentação, orientação acadêmica de trabalhos e pesquisa, no caso, em Educação e, ainda mais precisamente, em Educação Profissional e Tecnológica. Ao analisar, indubitavelmente, acaba-se, comparando, descobrindo, conhecendo e estes elementos podem vir a integrar o modo próprio de pesquisar.

Ao descrever a pesquisa, ou seja, a Análise dos Movimentos de Sentidos ${ }^{10}$, e os dados produzidos, inicia-se pela apresentação da quantidade de trabalhos analisados, quanto ao ano de produção, no período de 2009 a 2019:

Gráfico 01 - Quantidades de trabalhos acadêmicos encontrados em instituições de Ensino Superior gaúchas Dissertações (D) e Teses (T), divididadas por ano de conclusão

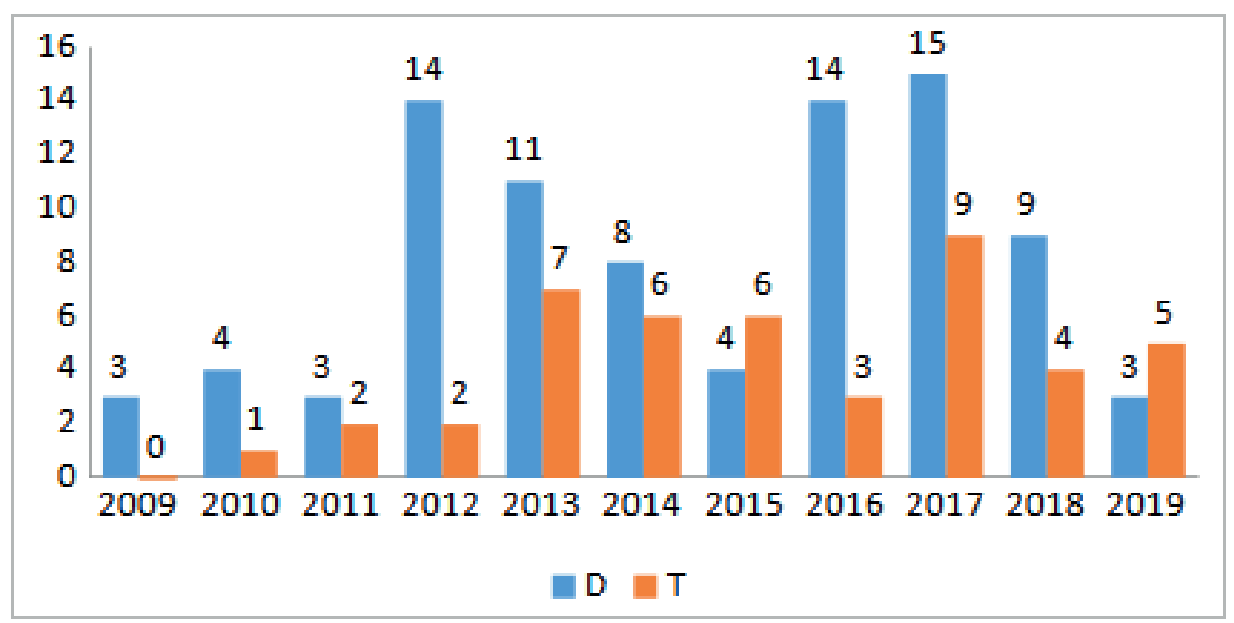

Fonte: Os autores, com base nos trabalhos analisados, 2020.

9 Em decorrência de se perceber que os trabalhos apresentavam dificuldade em reconstituir a historicidade da EPT no RS, realizou-se outra pesquisa da qual resultou livro sistematizando como aconteceu a implementação desta modalidade no Estado, constante nas referências como Ferreira, 2020b.

10 Dadas as características da Análise dos Movimentos de Sentidos (AMS), não há intenção de apresentar uma análise detalhada dos temas abordados, das metodologias aplicadas nas produções analisadas ou mesmo das teorias que embasaram as pesquisas. Neste artigo, então, não é apresentada uma análise mais profunda sobre os textos coletados. A AMS trabalha com os sentidos decorrentes da análise, pressupondo esses aspectos e detalhando-os quando necessário. Apresenta-se essa explicação para dirimir quaisquer equívocos, posto que analisar um estudo realizado com base no fundamento teórico-metodológico, AMS, é diferenciado de analisar visando a compor um estado da arte ou estado do conhecimento. 
Observa-se maior quantidade de produção nos anos de 2012, 2016 e 2017. A explicação encontrada, durante a pesquisa, assenta-se em duas ocorrências:

a) em 2012, foram publicados muitos trabalhos, dissertações e teses, resultantes do acúmulo de pesquisa realizada com financiamento resultante da aprovação de projeto no Programa de Apoio ao Ensino e à Pesquisa Científica e Tecnológica em Educação Profissional Integrada à Educação de Jovens e Adultos - PROEJA-CAPES/SETEC, conhecido como Edital PROEJA CAPES - SETEC, nº3/2006, pelo qual foi criada uma espécie de observatório do PROEJA no Estado, com atribuição inclusive de bolsas para pesquisadores realizarem pós-graduação. Foram lidos oito trabalhos relacionados a este Edital. Tais trabalhos foram desenvolvidos nos programas de pós-graduação das seguintes IES: Universidade Federal do Rio Grande do Sul (UFRGS) e Universidade do Rio dos Sinos (UNISINOS). Segundo texto produzido pelos pesquisadores, o objetivo que reuniu professores de universidades gaúchas foi: "[...] investigar diversos aspectos vinculados à implantação dos cursos do (PROEJA) nos Institutos Federais de Educação, Ciência e Tecnologia localizados no estado do Rio Grande do Sul" (FRANZOI; HYPOLITO; FISCHER; DEL PINO; SANTOS, 2010, p. 167). Outra intenção foi constituir "[...] um campo de estudo teórico-metodológico interdisciplinar, nascido da confluência da Educação Profissional e da Educação de Jovens e Adultos (EJA)" (FRANZOI; HYPOLITO; FISCHER; DEL PINO; SANTOS, 2010, p. 167). E, ainda, o projeto pretendeu, debater e subsidiar "[...]a formulação de políticas públicas na área da educação profissional integrada à educação básica, analisando os impactos do PROEJA para as instituições, para os professores e para os alunos envolvidos" (FRANZOI; HYPOLITO; FISCHER; DEL PINO; SANTOS, 2010, p. 167);

b) no ano de 2014 foi criado um programa de pós-graduação em Educação Profissional e Tecnológica, na Universidade Federal de Santa Maria, e as primeiras defesas de dissertações aconteceram entre 2016 e 2017.

Com relação aos aspectos teóricos e metodológicos descritos nos trabalhos lidos, é possível analisar vários movimentos de sentidos.

Parece haver certo padrão organizativo nos trabalhos. Há elementos constituintes da escrita que são recorrentes, repetem-se em vários trabalhos de diferentes IES. Analisou-se a recorrência desses elementos, como modo de avaliar os dispositivos de composição do texto, entendidos como afinados ao aporte teórico-metodológico da pesquisa realizada por aqueles pesquisadores, e chegou-se aos seguintes índices: 
Gráfico 02 - Elementos recorrentes na composição dos textos

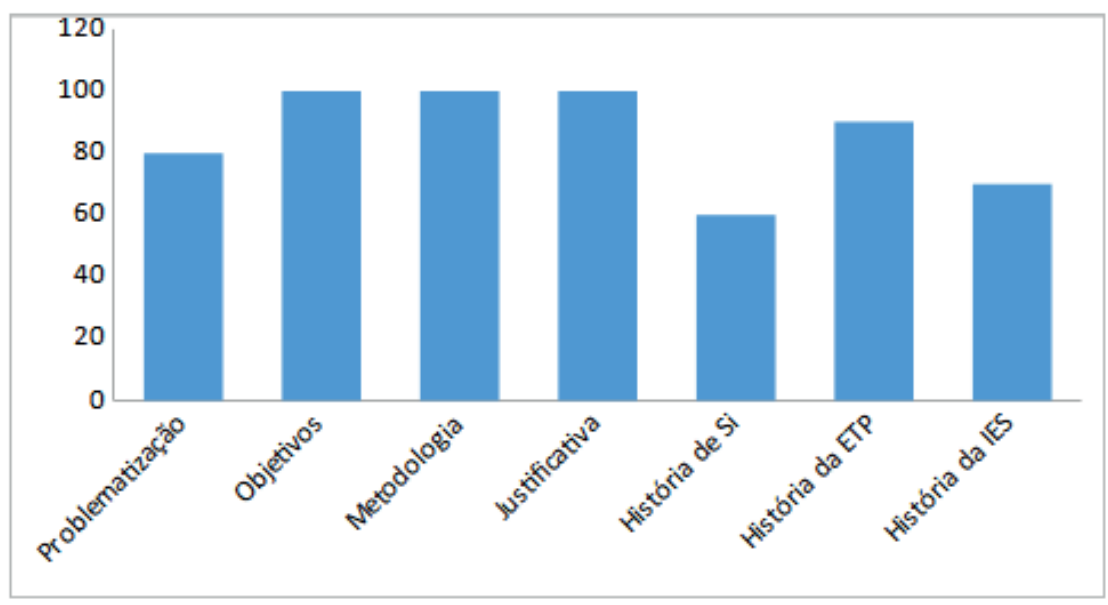

Fonte: os autores, com base nos trabalhos analisados, 2020.

Quanto a essa recorrência, interessante poder-se inferir que as dissertações e teses nos cursos de pós-graduação, integrantes da amostra estudada, apresentam uma indicação de estrutura comum. Na abordagem das temáticas escolhidas, são elaborados objetivos que visam ao encaminhamento de uma problematização. Dessa elaboração, resulta a delimitação de uma metodologia e esta é justificada pela demanda de estudo sobre a temática e sobretudo pela historicidade dos pesquisadores. Na sequência, há uma espécie de contextualização, na qual os autores relatam a historicidade da EPT e da IES onde realizaram o estudo, e seguem as análises resultantes da pesquisa realizada. Poder-se-ia denominar essa estrutura, devido à recorrência, de padrão e, lendo os trabalhos, constatou-se que, do total de cento e trinta e três, apenas dois, de algum modo não cumprem essa sequência, apresentando, em vez de capítulos, ensaios e, em vez de metodologia, narrativa sobre suas ações no campo de pesquisa.

De fato, é difícil pensar na organização do texto dissertativo ou do relatório de tese sem se partir de uma pergunta, para a qual se busca respostas e, por isso, elaboram-se objetivos. Sem que essa ação esteja descrita quanto aos aspectos teórico-metodológicos. Entretanto, outra leitura possível é compreender esse apego a uma estrutura padrão como resultante da incipiência da pesquisa na área da EPT. Ou seja, ainda não se tem uma elaboração teórico-metodológica proveniente dos estudos já realizados e tampouco capaz de sustentar a constituição de uma pesquisa própria e atinente à EPT, portanto, mantém-se a reprodução dos modelos de trabalho final já considerados tradicionais nas universidades, sem refletir ou propor outras possibilidades. Recentemente, teve-se acesso a livro lançado por pesquisadores do Instituto Federal Farroupilha, cujo título é "Metodologia(s) da pesquisa em Educação Profissional e Tecnológica" (BRANCHER \& CANTERLE \& MACHADO, 2019). Entretanto, uma leitura dinâmica do texto remete à percepção de que se tratam de metodologias da Pesquisa em Educação, portanto, ainda não são elaborações oriundas e 
representativas da pesquisa na Educação Profissional e Tecnológica, como campo ${ }^{11}$ específico dentro da pesquisa em Educação.

Esta discussão ${ }^{12}$ talvez seja inicial aqui, mas necessita acontecer. Manter-se-á a Pesquisa em Educação ou realmente é demandado criar-se uma pesquisa em Educação Profissional e Tecnológica? Estar-se-ia, quem sabe, neste caso, criando um subcampo e, quanto a isso, cabe o alerta de Bourdieu:

Existe um consenso, com efeito, de que a luta científica se torna cada vez mais intensa (apesar das conseqüências da especialização que tende a reduzir, sem cessar, o universo dos concorrentes pela divisão em subcampos cada vez mais estreitamente especificados) na medida em que a ciência avança ou, mais precisamente, na medida em que os recursos científicos acumulados aumentam e que o capital necessário para realizar a invenção se torna mais larga e uniformemente distribuído entre os concorrentes pela ampliação do direito de entrada no campo. (1983, p. 20)

Contrariamente, pensa-se que a questão não é relativa à criação do "subcampo", mas à especificidade. Enquanto a pesquisa sobre EPT não descrever seus próprios aportes teórico-metodológicos não assumirá seu lugar como campo científico, estando sempre à mercê de outros campos. Paralelamente à descrição destes aportes, cabe a elaboração de uma rede de pesquisa. Entende-se por redes de pesquisa, a associação de pesquisadores com interesse pela pesquisa em EPT, compondo uma comunidade acadêmica e esta inclui:

[...] grupo de pesquisa e o torna ainda mais coeso, mais integrado em torno de objetivos comuns, potencializando características individuais que se tornam vetores para a produção coletiva do conhecimento. Na comunidade, então, vai-se além, produzindo-se o entrecruzamento de leituras, argumentos, experiências, subjetividades que, ao se movimentarem, se recriam e demandam análise, interpretação, sistematização. (FERREIRA, 2017, p. 106)

A análise dos trabalhos revelou índices interessantes para se pensar como iniciar a articulação de uma rede de pesquisadores no Estado do Rio Grande do Sul13. Ao ler os trabalhos, ela-

11 Campo é uma noção proposta por Bourdieu: "espaço relativamente autônomo, esse microcosmo dotado de suas leis próprias" (2004, p. 20).

12 Reitera-se o quanto é incipiente essa reflexão ainda, pois, é corrente a inserção das pesquisas sobre EPT na pesquisa em educação, e, dada a novidade que é a Rede Federal de Educação e, do mesmo modo, os estudos sobre a Educação Profissional no Brasil, como modalidade, não se tem uma tradição acadêmica no Rio Grande do Sul que permita, com base no conjunto da produção, a confecção de outro modo de pesquisar, consonante com as especificidades da Educação Profissional.

13 Em decorrência também desse estudo, em 2020, constituiu-se a Rede Gaúcha de Estudos e Pesquisas sobre Educação Profissional e Tecnológica - REGEPT, com quinze grupos de pesquisa signatários, que estão trabalhando em conjunto. Maiores informações podem ser obtidas no site da REGEPT: https://www.ufsm.br/ cursos/pos-graduacao/santa-maria/ppge/2020/07/12/rede-gaucha-de-estudos-e-pesquisas-sobre-educacao-profissional-e-tecnologica/ 
borou-se uma espécie de sociograma, indicando quais universidades recebem convites e quais expedem convites para que outros autores componham as comissões avaliativas das dissertações e teses. Tal ação visou a aprofundar os sentidos quanto às relações de pesquisa entre os programas de pós-graduação. Ou seja, intencionou estudar os sentidos de rede de pesquisa evidenciados ou não no trabalho acadêmico. Obteve-se as seguintes figuras como resultantes:

\footnotetext{
Figura 01: Articulações das comissões avaliativas de dissertações sobre a temática Instituto Federal de Educação Profissional e Tecnológica no Rio Grande do Sul
}

\section{DISSERTAÇÕES}

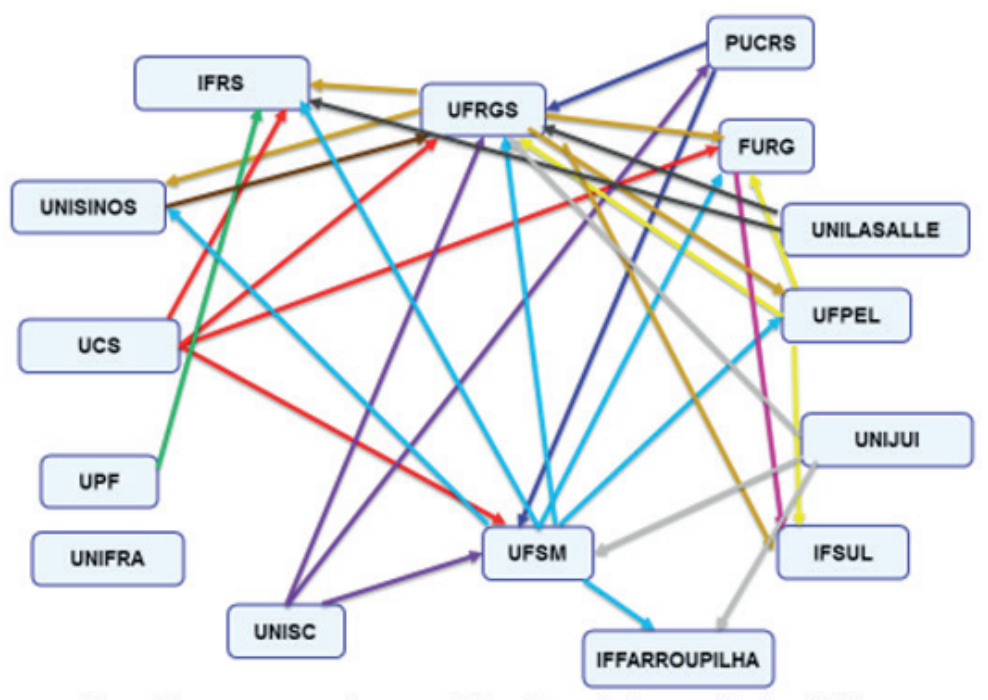

Fonte: Os autores, com base nos dados dos trabalhos analisados, 2020.

O emaranhado de setas apresenta a possibilidade de se perceber que a Universidade Federal do Rio Grande do Sul (UFRGS), o Instituto Federal Rio Grande do Sul, a Universidade de Rio Grande (FURG), o Instituto Federal Sul-Rio-Grandense (IFSUL) e a Universidade Federal de Santa Maria (UFSM) receberam mais pedidos de bancas, no período analisado, que as demais IES. O que essa constatação indica? Indica, minimamente, que estas instituições, no período de 2009 a 2019 a) abrigavam pesquisadores que estavam produzindo pesquisas que as credenciaram para avaliar os estudos realizados; b) que pesquisadores destas IES mantinham contato com os demais; c) que estas IES mantinham entre si atividades acadêmicas que aproximavam os sujeitos. Tais aspectos permitiram que, naquele momento, pesquisadores e temáticas se aliassem devido aos seus interesses de pesquisa. Do mesmo modo, tanto os Institutos Federais no Rio Grande do Sul ${ }^{14}$, quanto a UFSM mantêm programas de pós-graduação com especificidade temática em Educação Profissional e Tecnológica. A UFRGS e a FURG, por sua vez, mantêm linhas de pesquisa em seus programas com intensa produção sobre EPT.

14 Está-se referindo ao Mestrado Profissional em Educação Profissional e Tecnológica (ProfEPT), criado pela Resolução do Conselho Superior, no 161 (IFES, 2016), desenvolvido em Rede por 40 Instituições Associadas da Rede Federal de Educação Profissional e Tecnológica no país, localizadas nos 26 Estados da Federação e no Distrito Federal (CASTAMAN; PASQUALLI; VIELLA, 2019). 
As características indicativas de uma rede de pesquisadores, a partir da composição das comissões avaliativas em bancas de defesa se alteraram, no mesmo período, no tocante à defesa de teses:

Figura 02: Articulações das comissões avaliativas de teses sobre a temática Instituto Federal de Educação Profissi Tecnológica no Rio Grande do Sul

\section{TESES}

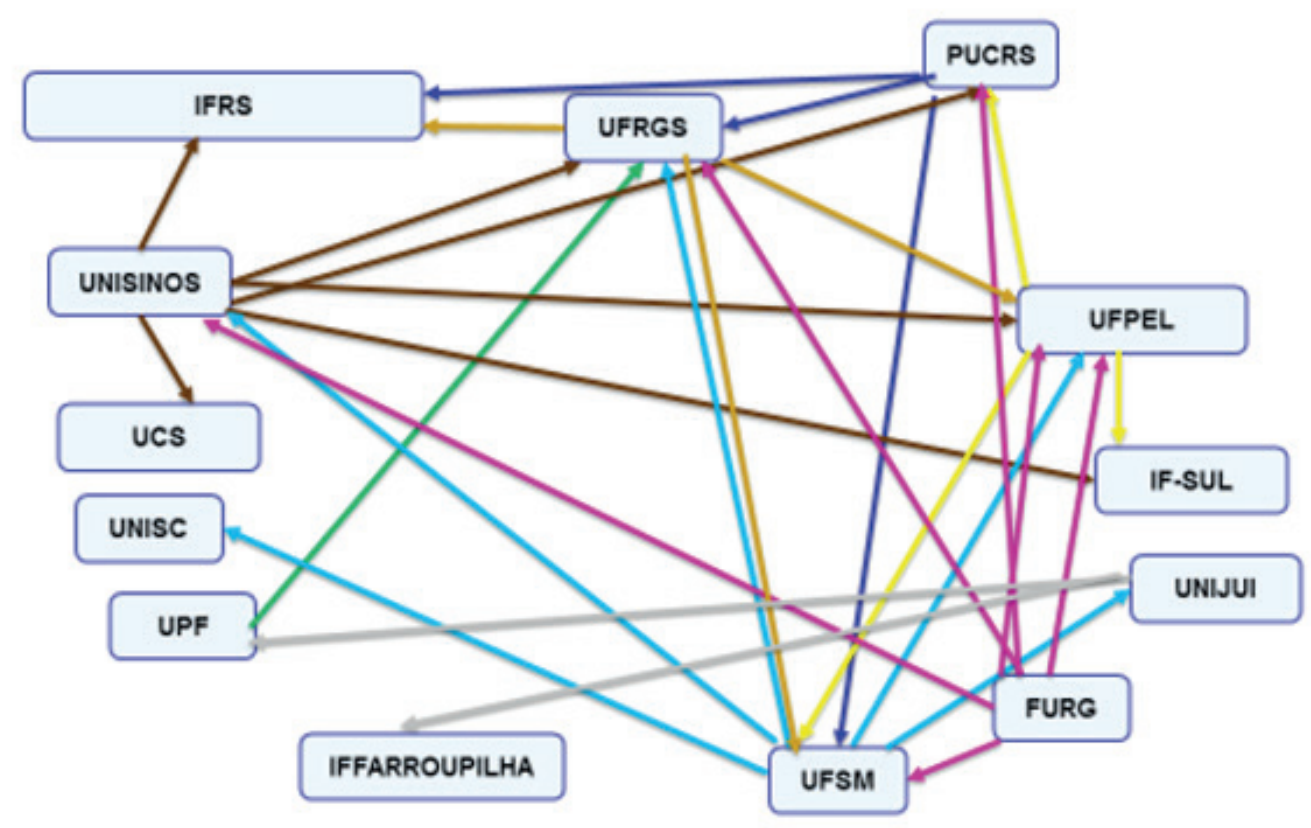

Fonte: Os autores, com base nos dados dos trabalhos analisados, 2020.

Observa-se, com referência à avaliação de teses, que a Universidade Federal do Rio Grande do Sul (UFRGS) e a Universidade Federal de Santa Maria (UFSM) continuam sendo muito solicitadas, mas desponta a Universidade Federal de Pelotas (UFPEL) também como uma IES que recebe convites para participação em bancas. A explicação pode ter a ver com o fato que estas IES ofertam, há mais tempo que as outras, Doutorado em Educação, nos quais há linhas de pesquisa que abrigam estudos sobre Educação Profissional e Tecnológica.

Com estas duas figuras, vislumbrou-se potencialidade na formação de uma rede de pesquisa sobre EPT, o que, em decorrência, exige maiores articulações com base na produção acadêmica, seja na composição de bancos de dados coletivos, seja na elaboração de eventos, seja na participação nos cada vez mais raros editais de financiamento de pesquisa. Esta potencialidade necessita ser amparada por iniciativas, talvez. E, por isso, reitera-se a razão para estudos como este aqui relatado.

Ainda com relação à composição de um aporte teórico-metodológico para a pesquisa sobre EPT e sobre os institutos federais, analisados os trabalhos, sob a perspectiva dos aportes teóricos, observou-se que apenas um autor gaúcho está entre os mais citados, ou seja, com mais de vinte citações, nos cento e trinta e três trabalhos analisados. E está, 
provavelmente, porque é um autor cuja obra está relacionada a seu trabalho na Secretaria de Educação Profissional e Tecnológica (SETEC) do Ministério da Educação, na época da implementação da Rede de Educação Profissional e Tecnológica, registrando, na forma de produções acadêmicas, este processo. Os demais autores muito citados produzem suas obras tendo por referência a EPT no contexto nacional. Essa análise com relação aos autores de obras sobre EPT ficou assim organizada em gráfico:

Gráfico 03 - Autores de obras sobre EPT, mais citados nos trabalhos analisados

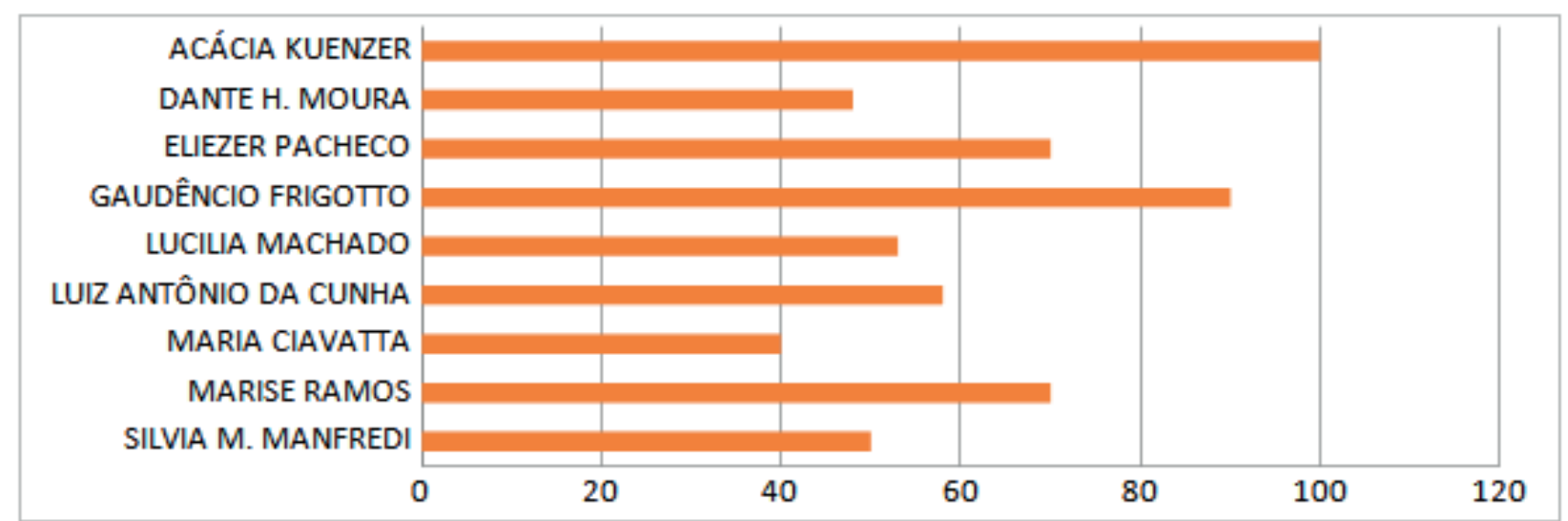

Fonte: os autores, com base nos trabalhos analisados, 2020.

Uma reorganização dos dados relativos aos autores permite perceber-se algo implícito. Se forem somadas as citações de um grupo de autores que produzem juntos, porque participam do mesmo grupo de pesquisa, a saber: Gaudêncio Frigotto, Maria Ciavatta e Marise Ramos, acrescentando ainda as recorrências de textos escritos por estes três autores juntos, sem dúvida, poder-se-ia afirmar: no RS, a EPT é abordada a partir da obra destes três autores que, juntos, superam largamente as citações de outros autores. Tal constatação leva a perguntar-se sobre a emergência de configurar-se no Estado um acervo bibliográfico relativo à EPT local. Destarte, conclui-se que, embora tenha-se vivenciado a produção de tantos trabalhos importantes de pesquisa sobre EPT, nos últimos dez anos no RS, ainda não se tem uma produção acadêmica gaúcha conhecida e divulgada nas dissertações e teses, que contribua para substanciar a elaboração acadêmica sobre a EPT gaúcha.

Outro dado interessante é a recorrência da citação das obras de Dermeval Saviani. Este autor, Professor Emérito da Universidade de Campinas, não foi incluído na figura anterior, porque, em conjunto, sua obra não aborda somente EPT, mas preponderantemente versa sobre políticas educacionais, historicidade e a relação educação e trabalho. Ainda assim, sozinho, é o mais citado, inclusive mais citado que os autores referidos no parágrafo anterior, com cento e quatorze ocorrências. Entre estas, o seu conhecido texto "Trabalho e educação: fundamentos ontológicos e históricos" (SAVIANI, 2007) é referendado em trinta e um trabalhos. 
Desse modo, caracterizou-se, dentro das possibilidades deste artigo, genericamente, os textos estudados, indicando os movimentos de sentidos relativos a como se organizam e indicam aportes teóricos e metodológicos. Este é um modo diferenciado de analisar, pois não objetiva abordar as temáticas estudadas em cada texto, mas as similaridades, diferenciações, indicações que a leitura revela como movimento, como sentidos possíveis e reveladores da produção como um todo. Na seção seguinte, apresenta-se uma retomada dos aspectos metodológicos e uma síntese do estudo até agora realizado, destacando as considerações mais gerais produzidas a partir da pesquisa na forma como foi encaminhada, através da Análise de Movimentos de Sentidos.

\section{CONSIDERAÇÕES FINAIS SOBRE OS DADOS PRODUZIDOS: O ESTUDO SOBRE OS IFS NA PÓS-GRADUAÇÃO}

Como se argumentou, o texto objetivou apresentar uma análise dos sentidos sobre os IFs gaúchos, com base na produção acadêmica na pós-graduação em IES do Rio Grande do Sul. Como tal, contribui para o acervo acerca dessa temática, relacionada diretamente à Educação Profissional e Tecnológica no Estado, além de indicar modos de realizar um estudo com um volume expressivo de dados. Ao indicar, contribui também para os estudos sobre Pesquisa em Educação, mais propriamente, Educação Profissional e Tecnológica.

Sobre os IFS no Estado, encontrou-se, então, como resultado, no período da pesquisa, centro e trinta e três trabalhos. As temáticas estudadas variam muito e é possível classificá-las em dois grupos: a) descrição da historicidade e do contexto dos IFS, constituindo-se em importantes registros da implantação e historicidade; b) temáticas estudadas a partir dos IFS como contexto e que, possivelmente, pudessem ser analisadas em quaisquer outros contextos institucionais.

Quadro 03 - Temáticas abordadas nas dissertações e teses com relação à implantação e historicidade dos IFs.

\begin{tabular}{|l|l|l|l|}
\hline & IFRS & IFSUL & IFFAR \\
\hline $\begin{array}{l}\text { Políticas educacionais: PROEJA, PRONATEC, MULHERES MIL, } \\
\text { PIBID, Bolsa Família }\end{array}$ & $\mathrm{x}$ & $\mathrm{x}$ & $\mathrm{x}$ \\
\hline Implantação dos IFS & $\mathrm{x}$ & $\mathrm{x}$ & \\
\hline Ensino Básico Técnico e Tecnológico & $\mathrm{x}$ & $\mathrm{x}$ & $\mathrm{x}$ \\
\hline Cursos Superiores de Tecnologias, Licenciaturas & $\mathrm{x}$ & & \\
\hline Tecnologias educacionais, EAD, Rede E-Tec & $\mathrm{x}$ & $\mathrm{x}$ & $\mathrm{x}$ \\
\hline Currículo Integrado & $\mathrm{x}$ & $\mathrm{x}$ & $\mathrm{x}$ \\
\hline Educação Especial, inclusão e Tecnep & $\mathrm{x}$ & $\mathrm{x}$ & $\mathrm{X}$ \\
\hline
\end{tabular}

Fonte: Os autores, com base nos dados dos trabalhos analisados, 2020. 
Estes temas são amplos, descritos com base nas políticas educacionais, nos regulamentos e projetos pedagógicos dos IFs e objetivam caracterizar como se elaboraram nos contextos específicos destas instituições.

Com relação ao segundo bloco temático, os trabalhos abordam sobre:

Quadro 04 - Temáticas gerais abordadas nas dissertações e teses

\begin{tabular}{|l|l|l|l|}
\hline & IFRS & IFSUL & IFFAR \\
\hline Formação e trabalho dos professores & $\mathrm{x}$ & $\mathrm{x}$ & $\mathrm{x}$ \\
\hline Educação, trabalho dos estudantes & $\mathrm{x}$ & $\mathrm{x}$ & \\
\hline Educação do campo & & & $\mathrm{x}$ \\
\hline Educação indígena & $\mathrm{x}$ & & \\
\hline Didática e Metodologia: avaliação, estágio, jogos, leitura & & $\mathrm{x}$ & $\mathrm{x}$ \\
\hline Gestão educacional & $\mathrm{x}$ & $\mathrm{x}$ & $\mathrm{x}$ \\
\hline Acesso, permanência e evasão & $\mathrm{x}$ & $\mathrm{x}$ & $\mathrm{x}$ \\
\hline Áreas do conhecimento: Língua Inglesa, Educação Física & $\mathrm{x}$ & & $\mathrm{x}$ \\
\hline
\end{tabular}

Fonte: Os autores, com base nos dados dos trabalhos analisados, 2020.

Uma análise dos movimentos de sentidos quanto às temáticas indicou que cerca de cinquenta por cento dos trabalhos dedicaram-se ao estudo de três temas: formação e trabaIho dos professores (25), currículo (16) e PROEJA (23). Os demais abordam diferenciadas temáticas.

Feito esse percurso e a sistematização realizada até o momento dos dados produzidos, é possível argumentar-se que:

a) O estudo da produção acadêmica no âmbito da pós-graduação assemelha-se a um estágio em que os pesquisadores se permitem com o intuito de conhecer e, conhecendo, aprendem e avaliam sua própria pesquisa;

b) Realizar esta produção como "estado do conhecimento" ou "estado da arte" é uma possibilidade. Entretanto, tais pesquisas, se efetivadas na Internet, podem ser limitadas pelas contingências dos sites de busca, pois os repositórios não raramente se encontram desatualizados ou incompatíveis com o Banco de Teses da Capes e este, por sua vez, diferenciado daqueles, com dados faltantes;

c) Realizar uma análise dos movimentos de sentidos, nesta perspectiva, apresenta-se como uma possibilidade mais efetiva de, selecionada uma amostra dos trabalhos, mediante critérios rigorosamente elaborados e análises teoricamente fundamentadas, estudar a produção acadêmica. Este estudo, como tal, será sempre um estudo possível, provisório e circunstancial, posto que, alterados os critérios que lhe deram origem, especialmente a época e as temáticas, alterar-se-á;

d) Com exceção dos trabalhos produzidos durante a vigência do Edital PROEJA CAPES - SETEC, $n^{\circ}$ 03/2006, que, além da produção gerada, organizada em 
torno da temática PROEJA, permitiu uma aproximação entre pesquisadores e instituições participantes, os demais trabalhos estão circunscritos às linhas ou grupos de pesquisas, dentro dos programas de pós-graduação, sem declarada articulação com os demais, indicando não haver uma rede ou uma composição de pesquisadores e temas estudados coletivamente. Em decorrência deste estudo, então, iniciou-se a Rede Gaúcha de Estudos e Pesquisas sobre Educação Profissional e Tecnológica - REGEPT.

Especificamente com relação a esta pesquisa, constatou-se que, sobre os Institutos Federais de Educação, Ciência e Tecnologia no Rio Grande do Sul,

a) Os trabalhos atêm-se, em noventa por cento dos casos, a registrar a historicidade do autor(a)/pesquisador(a) e justificar, com base nesta narrativa, a pesquisa realizada;

b) Dez por cento dos trabalhos registram a historicidade do lócus de pesquisa, mas vão além: emitem análises, muitas vezes, criticando, propondo alternativas, sobre os temas estudados no contexto dos institutos;

c) Os estudos foram realizados no contexto dos IFs gaúchos. Apenas cinco trabaIhos abordaram todos os IFs e todos os campis. A maior parte registra pesquisa realizada em um campus, normalmente próximo à IES onde o/a pesquisador/a (acadêmico/a da pós-graduação) estuda ou é o campus onde o/a pesquisador/a trabalha. O IFSUL Pelotas é o locus que abrigou maior quantidade de estudos, com dezessete pesquisas naquele campus. Seguem o campus IFRS/Bento Gonçalves e IFRS/Porto Alegre com nove pesquisas. Com nove também, encontrou-se o campus São Vicente do Sul, do IFFar;

d) Cabe destacar que noventa e três autores das dissertações ou teses lidas trabaIham nos Institutos, sendo sessenta e um professores, um professor substituto e trinta e um técnicos, ou administrativos ou em assuntos educacionais. Um dos autores, ao tratar sobre Ensino Médio Integrado, descreve, ao longo do trabalho o fato de pesquisar e, ao mesmo tempo, trabalhar no IF: "Ao mesmo tempo que tal condição me facilitou acesso a documentos (mesmo que estes sejam públicos, alguns desses não são de fácil acesso à população em geral) e fontes, colocou-me em diálogo constante com as minhas preferências e convicções pessoais" (MARÇAL, 2015, p. 34).

Com essa sistematização, não somente foi possível conhecer a produção relativa aos IFs, mas descrever como estão se configurando no Estado a) a criação de um campo do conhecimento sobre Educação Profissional e Tecnológica - EPT e b) o reconhecimento e estabilização dos institutos federais, nessa última década, como ambientes institucionalizados de educação, aspectos estes com implicação direta para a produção científica na pós-graduação. 
De modo geral, há que reiterar o quão produtivo é conhecer a produção realizada por colegas acerca de um tema de interesse. Doravante, será mais fácil escolher e descrever interesses de pesquisa, pois se sabe com quais interlocutores se pode estabelecer diálogo e o quanto estes interlocutores já produziram, evitando-se repeti-los. Cabe agora caminhar no sentido das demandas que a pesquisa apontou: a consolidação da rede de pesquisadores e de produções mais articuladas sobre Educação Profissional e Tecnológica e, inserida nela, sobre os Institutos Federais de Educação no Estado. 


\section{REFERÊNCIAS}

BOURDIEU, Pierre. Os usos sociais da Ciência: por uma sociologia clínica do campo científico. São Paulo: UNESP, 2004.

BOURDIEU, Pierre. "O campo científico". In: ORTIZ, R. (Org). Pierre Bourdieu: sociologia. São Paulo: Ática, 1983. p. 122-155.

BRASIL. Ministério da Educação. Decreto $n^{\circ}$ 5.478, de 24 de junho de 2005. Institui, no âmbito das instituições federais de educação tecnológica, o Programa de Integração da Educação Profissional ao Ensino médio na Modalidade de Educação de Jovens e Adultos - Proeja. Brasília, DF

BRASIL. Ministério da Educação. Expansão da Rede Federal. 2014. Disponível em: http://redefederal.mec.gov.br/expansao-da-rede-federal . Acesso em: 13 de dezembro de 2019.

BRASIL. Ministério da Educação. Secretaria de Educação Profissional e Tecnológica. Concepções e Diretrizes da Educação Profissional e Tecnológica: política da EPT 2003- 2010. Acesso em: 13 de maio de 2020.

BRASIL. Ministério da Educação. Secretaria de Educação Profissional e Tecnológica. Diretrizes e Políticas da Educação Profissional e Tecnológica: 2003-2010. Acesso em: 13 de dezembro de 2019.

BRASIL. Presidência da República. Lei n 11.892 de 29 de dezembro de 2008. Institui a Rede Federal de Educação Profissional, Científica e Tecnológica, cria os Institutos Federais de Educação, Ciência e Tecnologia. Brasília, 2008.

BRASIL. Subchefia de Assuntos Parlamentares. EM Interministerial n 00118/2008/MP/MEC de 19 de junho de 2008. Brasília, 2008. Disponível em < http://www.planalto.gov.br/ccivil_03/projetos/EXPMOTIV/EMI/2008/118\%20-\%20MP\%20MEC.htm >. Acesso em: 13 de agosto de 2019.

Catálogo de Teses e Dissertações - CAPES. Disponível em: < https://catalogodeteses.capes.gov. br/catalogo-teses/\#!/> . Acesso em: 20 de fevereiro de 2019.

CASTAMAN, Ana Sara; PASQUALLI, Roberta; VIELLA, Maria dos Anjos Lopes. Formação do mestre em educação profissional e tecnológica - PROFEPT: reflexões sobre a didática. Revista Cocar, v.13, n. 26, p. 125-141, Maio-Ago, 2019.

FERREIRA, Liliana Soares. "Comunidade acadêmica: a orientação como interlocução e como trabalho pedagógico”. Acta Scientiarum, jan - mar 2017. pp 103-111.

FERREIRA, Liliana Soares. Discursos em análise na pesquisa em educação: materialidades, compreensões e possibilidades. Revista Brasileira de Educação. Rio de Janeiro, 2020a, vol. 25, p.1-18.

FERREIRA, Liliana Soares. Educação Profissional e Tecnológica no Rio Grande do Sul. Curitiba: Editora CRV, 2020b. 
FONTOURA, Julian Silveira Diogo de Ávila. A gestão da Educação Superior em contextos emergentes: a perspectiva dos coordenadores dos Cursos Superiores de Tecnologia do IFRS - Campus Porto Alegre. Dissertação. Programa de Pós-graduação em Educação, Pontifícia Universidade Católica/PUCRS, Porto Alegre, 2018.

FRANZOI, Naira, Lisboa. HYPOLITO, Álvaro Moreira. FISCHER, Maria Clara Bueno, DEL PINO, Mauro, SANTOS, Simone Valdete dos. Escola, Saberes e Trabalho: a pesquisa do PROEJA no Rio Grande do Sul. Educação e Realidade. V. 35, n. 01. 2010. p. 167-186.

GONÇALVES, Lucaires Czermainski. A Formação Omnilateral e os desafios para o ensino médio de nível técnico no mundo atual: limites e possibilidades da omnilateralidade no IFSUL. Dissertação. UFPE, Pelotas, 2017.

KOSIK, Karel. Dialética do Concreto. São Paulo: Paz e Terra, 2011.

MARCAL, Fabio Azambuja. O ensino médio integrado no IFRS enfrentando a dualidade. Tese, Doutorado em EDUCAÇÃO, UFRGS, 2015.

MINEIRO, Eliane Cristina Gualberto Melo; LOPES, Frederico Antonio Mineiro; SALES, Sheila Cristina Furtado. "Mapeamento das produções acadêmicas sobre os Institutos Federais de Educação, Ciência e Tecnologia publicadas na ANPED e CAPES, no período de 2005 a 2015”. In: Seminário Gepráxis, Vitória da Conquista - Bahia - Brasil, v. 6, n. 6, p 944-956, 2017.

MOURA, Dante Henrique. Políticas Públicas para a Educação Profissional Técnica de Nível Médio nos anos 1990 e 2000: Limites e Possibilidades. In OLIVEIRA, R. de. Jovens, Ensino Médio e Educação Profissional: Políticas Públicas em Debate. Campinas, SP: Papirus, 2012.

PACHECO, Eliezer. Os Institutos Federais uma revolução na educação profissional e tecnológica. São Paulo, Moderna, 2011.

SAVIANI, Dermeval. "Trabalho e educação: fundamentos ontológicos e históricos”. In: Revista Brasileira de Educação. V. 12, n. 34, jan/ab 2007. pp 152-180.

SCHWEDE, Marcos Aurélio; LIMA FILHO, Domingos Leite. Os Institutos Federais de Eduação, Ciência e Tecnologia: dos motivos para a sua constituição à produção da ciência e da tecnologia. In: Educere et educare. UNIOESTE. Vol. 11 Número 23 Jul./dez. 2016. Pp. 1-12.

TORRES, Carlos. Alberto. Estado, privatização e política educacional elementos para uma crítica do neoliberalismo. In: APPLE, M. et al. Pedagogia da exclusão: o neoliberalismo e a crise da escola pública. Petrópolis, RJ: Vozes, 1995. p. 109- 136.

TURMENA, Leandro; AZEVEDO, Mário Luiz Neves. de. A expansão da Rede Federal de Educação Profissional, Científica e Tecnológica: os Institutos Federais em questão. In: Revista Diálogo Educacional, Curitiba, v. 17, n. 54, p. 1067-1084, jul./set. 2017 